\title{
Evaluation and Adjustment of Coordinated Development between Land Use and Eco-Environment in Wuxi City*
}

\author{
Hua Sun ${ }^{1}$, Yan Liu ${ }^{2}$, Hailang Pan $^{3}$, Jing Zhao ${ }^{1}$, Qingzeng Qu ${ }^{1}$, Fengxiang $\operatorname{Han}^{4}$ \\ ${ }^{1}$ College of Land Management, Nanjing Agricultural University, Nanjing, China; ${ }^{2}$ Library of Nanjing Agricultural University, \\ Nanjing, China; ${ }^{3}$ School of Automation, Nanjing University of Science and Technology, Nanjing, China; ${ }^{4}$ Institute for Clean Energy \\ Technology, Mississippi State University, Starkville, USA. \\ E-mail: sh@njau.edu.cn, hailangpan@163.com, han@icet.msstate.edu
}

Received August $10^{\text {th }}, 2010$; revised September $22^{\text {nd }}, 2010$; accepted November $2^{\text {nd }}, 2010$.

\begin{abstract}
The purpose of this paper is to assess the coordinated development degree of land use and eco-environment in Wuxi City and choose the appropriate adjustment mode. Methods employed include documentation analysis, the coordinated development degree model analysis and BP neural network model analysis. The result shows that the coordinated development degree of land use and eco-environment in Wuxi City presents overall ever-increasing trends and that the overall consideration mode can reduce the contradiction between land use and eco-environment, which is a suitable mode for Wuxi City. It is concluded that the coordinated development degree model and BP neural network model have high reliability and practicability in evaluating and adjusting the coordinated development degree of land use and eco-environment in Wuxi City.
\end{abstract}

Keywords: Coordinated Development, Evaluation, Adjustment, Wuxi City

\section{Introduction}

With the development of research projects, such as "International Geosphere and Biosphere Program" (IGBP) and the "Global Environmental Change Program in the humanities" (IHDP), etc. [1,2], the influence of land-use change on the ecological environment have been extensively studied [3-6]. However, few studies focused on the coordination of the relationship between land - utilization and ecological environment, especially in regulative research of coordinated development of land use and ecological environment. In Wuxi City, due to a high level of economic development, population density, ecological and environmental problems were highlighted. This paper explores the evaluation and adjustment of the coordinated development of land use and ecological environment in Wuxi City as an example, to provide a scientific basis for sustainable development, and to lay the

\footnotetext{
*The manuscript was sponsored by the humanities and social scientific research project in 2010 funded by Ministry of Education of the P. R. Chin, under Grant No. 10YJA630138 - "environmental risk evaluation and adjustment mechanism research of typical brownfields on Taihu Lake Basin" and National Science Foundation of China, under Grant No. 61075031
}

foundation for carrying out in-depth research in this area.

Wuxi City, Jiangsu Province, is located in the southeast of China. Geographic coordinates for east longitude $119^{\circ} 31^{\prime}-120^{\circ} 36^{\prime}$, north latitude $31^{\circ} 07^{\prime}-32^{\circ} 00^{\prime}$. The total area of the city is $4787.61 \mathrm{hm} 2$, with plains primarily, along with the distribution of some low mountains and residual mounds. Wuxi City has a northern subtropical maritime monsoon climate, with four distinct seasons, mild climate, plentiful sunshine and rainfall, long frost-free period, an average annual temperature of $15.7^{\circ} \mathrm{C}$, annual average sunshine of 1993.6 hours, annual rainfall of $1048 \mathrm{~mm}$, and annual frost-free period of about 220 days. Wuxi City has the high rate of land utilization and output and a large area of water. Therefore, it had a lack of land resources, resulting in more prominent ecological and environmental problems.

\section{The Determination of the Evaluation System}

Based on in-depth content of coordinated development between land use and eco-environment, this paper discuss economic and social development and eco-envi- 
ronment, which are two aspects related to evaluating the coordinated development of land use and eco-environment. Learning from similar studies on the index system, taking into account the actual situation in Wuxi City and the accessibility of data, the study established the evaluation index system of coordinated development of land use and eco-environment, from two sub-systems of the land-use system and ecological environment system. The system was broken down into 3 levels: target Layer, guidelines layer and index layer as shown in Table 1.

\section{The Evalution Model of Coordinated Development Degree}

The coordinated degree and model of coordinated development degree [7] will be employed in three present studies. It comprehensively evaluated the development level of land use subsystems and integrated environment subsystem and the coordinated development degree of the two systems. This model included the following sections:

\subsection{Comprehensive Evaluated Functions of Land Use $f(x)$ and Comprehensive Evaluated Functions of Eco-Environment g(y)}

Composite score of the level of land use and ecological environment, respectively, displays the level of land use and he development degree of ecological environment, while they are the basis for calculating integrated benefit index, land use and eco-environmental. The formulas are:

$$
f(x)=\sum_{i=1}^{m} W_{i} x_{i} \quad g(y)=\sum_{j=1}^{n} W_{j} y_{j}
$$

The formula: $f(x), g(y)$ are the composite score of the level of land-use, the composite score of the level of ecoenvironment, respectively; $\mathrm{m}, \mathrm{n}$ are the number of indicators of land use subsystems and the number of indicators of eco-environment subsystem, respectively; $W_{i}, W_{j}$ are the weight of each index of land use subsystems and the weight of each index of eco-environment subsystem, respectively; $x_{i}, y_{j}$ are the standard values of each index of land use subsystems and the standard values of each index of eco-environment subsystems, respectively [8].

\subsection{Comprehensive Evaluated Functions of Land Use and Eco-Environment}

$$
T=\alpha f(x)+\beta g(y)
$$

The formula: $\mathrm{T}$ is comprehensive benefit index of land use and eco-environment; $\alpha, \beta$ are, respectively, the weight of level of land use and the weight of level of eco-environment.

\subsection{Comprehensive Evaluated Functions of Coordinated Degree of Land Use and Eco-Environment}

Coordination degree is designed to reflect the level of coordinated degree of land use and eco-environment. The formula is:

$$
C=\left\{\frac{f(x) \cdot g(y)}{\left[\frac{f(x)+g(y)}{2}\right]^{2}}\right\}^{k}
$$

\begin{tabular}{|c|c|c|}
\hline Target Layer & Guidelines Layer & Index Layer \\
\hline \multirow{2}{*}{ Land-use subsystem } & Economic benefits of land use & $\begin{array}{l}\text { GDP per unit of land area, revenue per unit of land area, fixed asset investment } \\
\text { per unit of land area, industrial output per unit of land area, grain yield level, the } \\
\text { proportion of tertiary industry in GDP, growth rates of retail sales of social con- } \\
\text { sumer goods, Hoffman coefficient, annual profit and tax per unit of land area, } \\
\text { multiple cropping index }\end{array}$ \\
\hline & Social benefits of land use & $\begin{array}{l}\text { Per capita net income of rural residents, per capita disposable income of urban } \\
\text { residents, jenny coefficient, engers coefficient, population density, Scientific and } \\
\text { technical personnel for every thousand people, residents per-capita savings de- } \\
\text { posits, road line density, per unit of land area of employment and beds number } \\
\text { in thousands health institutions }\end{array}$ \\
\hline \multirow[t]{2}{*}{ Environment subsystem } & Eco-environmental quality & $\begin{array}{l}\text { Respirable particulate matter (PM10) on average, average daytime of noise in } \\
\text { regional environmental, emissions of industrial waste water, emissions of indus- } \\
\text { trial waste gas, industrial solid waste, compliance rate of drinking water quality, } \\
\text { compliance rate of urban ground-water quality, the amount of chemical fertilizer } \\
\text { in per unit of agricultural land, the amount of pesticide in per unit of agricultural } \\
\text { land }\end{array}$ \\
\hline & Eco-environment Construction & $\begin{array}{l}\text { Compliance rate of industrial wastewater discharge, comprehensive utilization of } \\
\text { industrial solid waste, treatment rate of urban sewage, rban gasification rate, } \\
\text { green coverage rate of built-up area, indexes of investment in urban environment } \\
\text { protection, output value of utilization of products made from "three wastes" } \\
\text { value of comprehensive products }\end{array}$ \\
\hline
\end{tabular}

Table 1. The evaluation index system of coordinated development between land use and eco-environment in Wuxi City. 
The formula: $\mathrm{C}$ is the coordinated degree of land use and eco-environment; $f(x), g(y)$ are, respectively, the composite score of the level of land-use, and the composite score of the level of eco-environment; $\mathrm{k}$ is the adjusted coefficient, $\mathrm{k}: 2$, the general value of 2 .

\subsection{Some Common Mistakes}

The degree of coordinated development reflects the level of coordinated development of land use and ecological environment. On the one hand, it reflects the synchronization of the changes in land use and eco-environment. On the other hand, it reflects the comprehensive level of the development of land use and eco-environment.

$$
D=\sqrt{C \cdot T}
$$

The formula: $D$ is the coordinated development degree of land use and eco-environment; $C$ is coordinated degree of land use and eco-environment; $T$ is comprehensive benefit index of land use and eco-environment.

\section{Analysis on the Results of Evaluation}

According to the evaluation, model can be calculated. composite score of the level of land-use $f(x)$, composite score of the level of eco-environment $\mathrm{g}(\mathrm{y})$, comprehensive benefit index of land use and eco-environment $T$, the coordinated degree of land use and eco-environment $C$, the coordinated development degree of land use and eco-environment from 1998 to 2007 in Wuxi City, as shown in Table 2.

From Table 2, we can see that the coordinated development degree was only 0.2732 in 1998 , but had reached 0.8193 in 2007 . Coordinated development degree of land use and eco-environment presented an ever-increasing trend in Wuxi City. It showed that the overall relationship of land use and eco-environment tended to ease up, land use and eco-environment were moving in the direction of coordinated development. This mainly resulted from the sharp increasing of social and economic benefits during the land use. In the same time, the quality of eco-environmental had also been improved, but what can not be overlooked is that the eco-environment still face $\mathrm{d}$ enormous pressure, the situation of eco-environmental protection was still not optimal.

\section{Regulation of Coordinated Development of Land Use and Ecological Environment}

\subsection{Choosing the Technical Methods for Regulating Coordinated Development}

It was to seek a better controlled strategy for regulating coordinated development of land use and eco-environment, which required a scientific and rational approach as support. This method should not only have qualitative methods such as expert advice and determination, but also should have a quantitative method. Because the coordinated development system which is composed of land use and eco-environment is complex, non-linear, etc, this study chose the artificial neural network model for controlled study.

Artificial neural network can approximate the structure and function of socio-economic systems. When the information was not complete, the program has a strong capacity in pattern recognition and decision-making. It has been widely used in the socio-economic system.

BP neural network was used by transmitting the error from output layer to input layer [9], which was a backpropagation algorithm (BP algorithm) [10] to establish multi-level and non-recycling network. The network was also continuously self-improved [11]. This algorithm has a strong applicability for the coordinated development systems of land-use and eco-environment, which were complex, non-linear and controllable.

\subsection{Selecting Controlled Indicators}

To ensure network uptime and system stability, this study chose the gray correlation method. According to transformed slandered data, calculated correlation coefficients and associated sequence, and formulate correlation matrix, the model quantified the process of dynamic development of the system, resulting in sorting out the relationship of main elements and identifying the most influential factors [12].

The paper concluded the correlation of land use subsystems and eco-environment subsystems by DPS v7.55.

Table 2. The coordinated development degree of land use and eco-environment in wuxi city.

\begin{tabular}{|c|c|c|c|c|c|c|c|c|c|c|}
\hline & 1998 & 1999 & 2000 & 2001 & 2002 & 2003 & 2004 & 2005 & 2006 & 2007 \\
\hline$f(x)$ & 0.0841 & 0.1145 & 0.1541 & 0.2588 & 0.3257 & 0.3872 & 0.5507 & 0.6412 & 0.7528 & 0.9074 \\
\hline$g(y)$ & 0.4557 & 0.4825 & 0.5368 & 0.5197 & 0.5388 & 0.6487 & 0.5414 & 0.5676 & 0.4967 & 0.5779 \\
\hline $\mathrm{T}$ & 0.2699 & 0.2985 & 0.3455 & 0.3892 & 0.4323 & 0.5179 & 0.5460 & 0.6044 & 0.6248 & 0.7426 \\
\hline $\mathrm{C}$ & 0.2766 & 0.3844 & 0.4807 & 0.7879 & 0.8821 & 0.8767 & 0.9999 & 0.9926 & 0.9178 & 0.9040 \\
\hline D & 0.2732 & 0.3387 & 0.4075 & 0.5538 & 0.6175 & 0.6738 & 0.7389 & 0.7745 & 0.7572 & 0.8193 \\
\hline
\end{tabular}


Then, other various factors were selected, including fixed asset investment per unit of land area, scientific and technical personnel for every thousand people, per capita disposable income of urban residents, population density, growth rates of retail sales of social consumer goods, and other main factors. Similarly, output value of utilization of products was made from "three wastes" value of comprehensive products. Similarly, indexes of investment in urban environment protection, urban gasification rate, respirable particulate matter (PM10) on average, the amount of chemical fertilizer in per unit of agricultural land and other main factors were selected from eco-environment subsystem.

\subsection{The Design of Network in the Model}

The paper set a three-layer network structure in controlled model for coordinated development of land use and environment in Wuxi City. These are: input layer, one hidden layer and output layer. We can see that the three layers of BP neural network model can achieve an arbitrary mapping $f:[0,1]^{n} \rightarrow R^{m}$ from Kolmogorov theorem. A hidden layer is sufficient.

According to controlled indicators selected from aforementioned, we can determine the number of neurons that are in the input layer to be 10 . The degree of coordinated development of land use and eco-environment can be used to reflect the level of coordinated development of land use subsystems and eco-environment subsystem. Therefore, the output layer of the model which is the degree of coordination development and the number of neurons is 1 . The number of neurons is determined by numerous experiments through the design process in hidden layer. BP network has better approximation effect to function when the number of neurons is 9 in the hidden layer. To sum up, the structure of BP network model was 10-9-1. Further, the hidden layer was using tansig which is "S" activated function; the output range was limited to $(0,1)$, so output layer was used logsig function; which could use Levenberg-Marquardt algorithm to ensure fast convergence of the network. This network design was completed by neural network toolbox 'nntool' of MATLAB 7.0.

\subsection{Training and Testing of the Network}

Because the reality system which was compounded by land use and eco-environment was very complex, the system needed approximate and abstract by BP neural network model. This paper made use of existing samples for the network training and testing. Initial weights of the network and biases were given random values, learning rate was 0.05 , the final learning error was 0.00001 . Data from 1998 to 2005 as training sample and data from 2006 to 2007 as testing sample were all treated through the differential standardization. After six times training for training samples, the network tended to stabilize and achieved target error. The training error curve is shown in Figure 1. The data from 2006 to 2007 were to test the model. Finally, it came to the network input, as shown in Table 3. In 2006, the relative error of simulation output value is 0.1301 . In 2007 , the relative error of simulation output value is 0.0075 .

The actual output Samples were basically consistent with the evaluated and calculated results. It showed that the performance of the network could get the requirements of practical applications, the training of network had succeeded and effected. The network already had good generalization capability and carry out carried the simulation calculations of coordinated development on degree different controlled modes.

\section{The Design of Control Mode}

This paper extrapolated the simulation calculations of coordinated development degree on Wuxi City from 2008 to 2012. Then, it settled the following control mode. The controlled parameter values of each controlled mode were comprehensively determined by the trend analysis and comparing the parameters of different types cities.

\subsection{High-Yield Model of Land Use}

This model emphasized on economic, social and highspeed development. Social resources and investment

Table 3. The test results of BP neural network model.

\begin{tabular}{cccc}
\hline Sample & Expected output & Actual output & Relative error \\
\hline 2006 & 0.7572 & 0.7474 & 0.0130 \\
2007 & 0.8193 & 0.8131 & 0.0075 \\
\hline
\end{tabular}

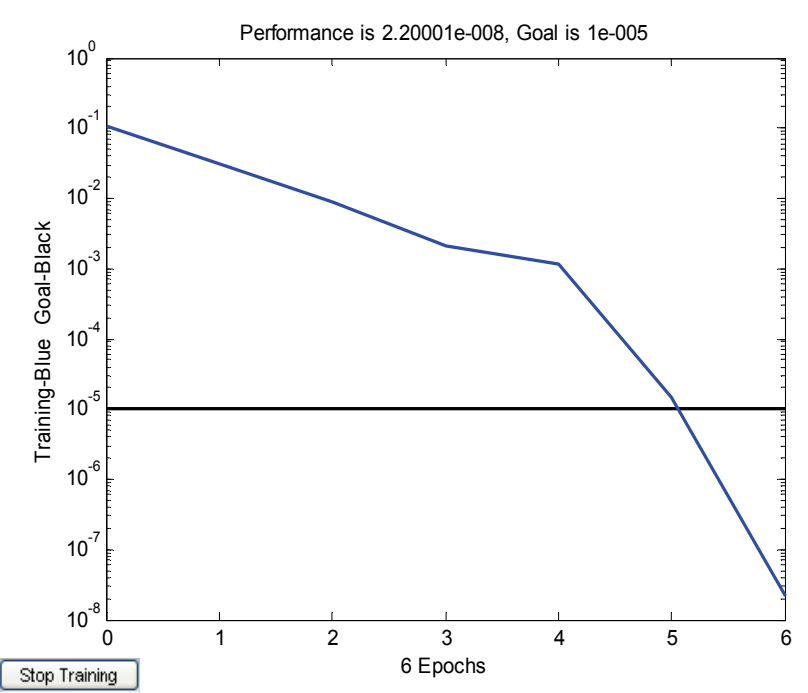

Figure 1. The training error curve of BP neural network. 
tilted to the social reproduction. The model also vigorously developed industry and the tertiary industry, accelerated infrastructure construction and occupied a large amount of agricultural land. So, eco-environmental protection has not done enough and environmental investments reduce using this model.

\subsection{Eco-Environmental Protection Model}

This mode emphasized protection on eco-environment and paid attention to economical land use. It also emphasized the protection on agricultural land, especially in the protection of arable land. The model minimized the construction land and other land use, slowed economic growth, limited the development of industry which causes serious harm to the eco-environment, strictly controlled population, positively developed eco-environment industry, increased the utilization rate of "three wastes" and enlarged investment of eco-environmental protection.

\subsection{Balanced Model}

This model focused on the coordinated development of land use output and eco-environmental protection to ensure the rational and efficient use of agricultural land and on developing secondary and tertiary industries, while focused on reducing the harm to eco-environment during industrial development. It strengthened the investment of eco-environment industry, optimized the structure of industry, and developed new industry which had high economic output and low environmental pollution.

\section{Analysis on the Result of Regulation of Coordinated Development}

As shown in Figure 2, it could conclude the simulation output of coordinated development degree of land use and eco-environment of Wuxi City, through using the trained BP neural network model and entering controlled parameters of each model.

The degree of coordinated development of high-yield model of land use declined from 2008. In 2012, it would be only 0.4730 which is mainly due to the fact that this pattern only focuses on the economic and social benefits. The model also neglected the investment and protection of eco-environment. Therefore, this model led to a high level of economy and the sharp decline in eco-environmental quality. Under the enormous pressure on the ecological environment, the stable high-output capacity of land use would also be affected. It was indicated that high-yield model of land use is a profit-oriented developed model; problems of land use and eco-environmental were not under control but had been intensified. If the model only cares for immediate benefits and ignores long-term development, it is an unreasonable development model which runs counter to sustainable development.

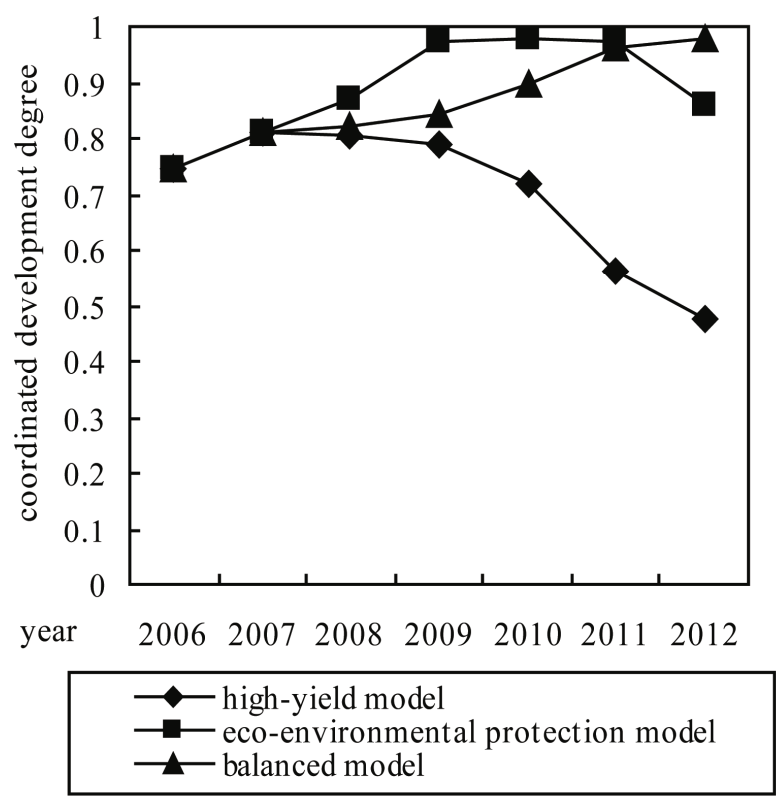

Figure 2. Change of coordinated development degree in three adjustment modes.

The degree of coordinated development of eco-environmental protection model was firstly increased and then decreased, mainly because this mode tended to reflect the economical use of land, focused on the protection of agricultural land and eco-environment and focused on controlling pollution. These improved the quality of eco-environment and provided a good eco-environment for the development of the economy and the social network. But the pattern was more restricting to the economic growth rate and the expense of economic interests in this region. The model could ease the contradiction between land use and eco-environment in shortterm, but low economic growth rate would lead to the level of regional economic development backward in long-term. It also could not continue to support the investment of eco-environmental. The contradiction between land use and eco-environment would be strengthened. So, eco-environmental protection model only developed eco-environment and did not consider economic development. Its legitimacy is also questionable.

The degree of coordinated development of balanced model was steady increased. It would rise to 0.9780 in 2012, which was mainly due to the coordinated development of land-use output and eco-environmental protection. It resulted in developing a new industry with high economic output and low environmental pollution. The level of output of land use was very high, which provided funding guarantees for the investment of eco-environment industry and the control of pollution. Good eco-environment also provided a foundation for rapid economic development. They mutually promoted to reach a win-win situa- 
tion of land use and eco-environment.

Balanced model is worth recommending because it eased the contradiction between land use and eco-environment.

Through analysis on the degree of the coordinated development of three-pattern, this study suggests that balanced model better coordinated the contradiction between land use and eco-environment. It could promote the improvement of environmental quality and the sustainable development of regional economy. It is more suitable for Wuxi City.

\section{Conclusions}

The coordinated development of land use and eco-environment is the inevitable requirement of regional sustainable development. This paper used coordinated development degree model to quantitatively assess the coordinated development land use and eco-environment of Wuxi City from 1998 to 2007.

The results show that the degree of coordinated development of land use and eco-environment presents ever-increasing trends. Land use and eco-environment is moving in a coordinated direction which benefits the city. These were mainly because of sharp increases of the social and economic benefits. But the eco-environment still faces a huge pressure. The situation of eco-environmental protection is still not optimal.

Based on the evaluation, coordinated development model of land use and eco-environment of Wuxi City was established by BP neural network. By comparing the change of the degree of coordinated development in three kinds of controlled models from 2008 to 2012, the study found that the contradiction between land use and eco-environment had been eased in the balanced model. Balanced model improved environmental quality and sustainable development of regional economy. It is a developed model which is more suitable for Wuxi City.

This article researched regulations of coordinated development of land use and eco-environment by using BP neural network method. It achieved good results and further expanded the content of coordinated development, which provided the reference value for similar research.

\section{REFERENCES}

[1] B. L. Turner, "Two Types of Global Environment Changes: Definition and Spatial-Scale Issues in Their Human Dimensions," Global Environmental Change, Vol. 1, No. 1, 1990, pp. 14-22.

[2] C. Q. Song and S. Y. Leng, "Some Important Scientific Problems of Integrative Study of Chinese Geography in 5 to 10 Years," Acta Geographica Sinica, Vol. 60, No. 4, 2005, pp. 546-552.

[3] E. Kalnay and M. Cai, "Impact of Urbanization and Land- Use Change on Climate," Nature, Vol. 423, No. 6939, 2003, pp. 528-531.

[4] F. Steiner and L. McSherry, "Cohen Land Suitability Analysis for the Upper Gila River Watershed," Landscape and Urban Planning, Vol. 50, No. 4, 2000, pp. 199-214.

[5] L. Sliva and D. D. W. Buffer, "Zone versus Whole Catchment Approaches to Studying Land Use Impact on River Water Quality," Water Research, Vol. 35, No. 14, 2001, pp. 3462-3472.

[6] P. Reidsma, T. Tekelenburg, M. van den Berg and R. Alkemade, "Impacts of Land-Use Change on Biodiversity: An Assessment of Agricultural Biodiversity in the European Union," Agriculture, Ecosystems and Environment, Vol. 114, No. 1, 2006, pp. 86-10.

[7] Z. B. Liao, "Quantitaitve Judgement and Classification System for Coordinated Development of Environment and Economy," Tropical Geography, Vol. 19, No. 2, 1999, pp. 171-177.

[8] F. R. Zhang, "Evaluation System and Method of Sustainable Use of Land," China Agriculture Press, Beijing, 2003.

[9] S. C. Li, etc., "An Analysis on Coordinated Development of the Ecological and Economic System around BoHai Area of Hebei Province," Geographical Research, Vol. 17, No. 4, 1998, pp. 351-358.

[10] Z. L. Jiang, "Introduction to Artificial Neural Networks," Higher Education Press, Beijing, 2001.

[11] H. L. Li, J. H. Gao, etc., "Land Sustainable Use Evaluation Based BP Neural Network in Henan Province," Territory \& Natural Resources Study, Vol. 4, No. 1, 2009, pp. 27-29.

[12] Q. Y. Tang and M. G. Feng, "DPS Data Processing System," Science Press, Beijing, 2006. 